University of Nebraska - Lincoln

DigitalCommons@University of Nebraska - Lincoln

June 1987

\title{
Comment on "Molecular Description of Two-Electron Atoms"
}

Anthony F. Starace

University of Nebraska-Lincoln, astarace1@unl.edu

Joseph H. Macek

University of Nebraska - Lincoln

Follow this and additional works at: https://digitalcommons.unl.edu/physicsstarace

Part of the Physics Commons

Starace, Anthony F. and Macek, Joseph H., "Comment on "Molecular Description of Two-Electron Atoms"'" (1987). Anthony F. Starace Publications. 32.

https://digitalcommons.unl.edu/physicsstarace/32

This Article is brought to you for free and open access by the Research Papers in Physics and Astronomy at DigitalCommons@University of Nebraska - Lincoln. It has been accepted for inclusion in Anthony F. Starace Publications by an authorized administrator of DigitalCommons@University of Nebraska - Lincoln. 


\section{Comment on "Molecular Description of Two- Electron Atoms"}

Feagin and Briggs ${ }^{1}$ have interpreted highly correlated states of three charged particles using a molecular model in which the distance $R$ between particles of like charge is an adiabatic parameter. They show that the model's potential curves, with adjustments to obtain the correct large- $R$ limit, ${ }^{1}$ are similar to hyperspherical diabatic potential curves, ${ }^{2-4}$ having the hyperradius $R$ as a parameter, for a variety of three-particle systems including $\mathrm{He}$, $\mathrm{H}^{-}$, and $\mathrm{Ps}^{-}$. Their potential curves (associated with two-electron bound and resonant states) are labeled by molecular quantum numbers. Significantly, the $2 s p+$ $\left({ }^{1} P\right)$ channel, which is known ${ }^{5}$ to take most of the oscillator strength in $\mathrm{He}$ and $\mathrm{H}^{-}$doubly excited states and which leads to a shape resonance ${ }^{6}$ in $\mathrm{H}^{-}$and $\mathrm{Ps}^{-}$, is identified with a $2 p \pi_{\mathrm{u}}$ state. This model gives new insights into the hyperspherical theory, but the wave functions in the two approximations differ substantially in the asymptotic region. Since this region is important for measurable quantities, this difference has experimental significance, which is discussed here.

$\mathrm{Data}^{7}$ on the ratio of $\mathrm{He}^{+}(2 p)$ and $\mathrm{He}^{+}(2 s)$ cross sections resulting from photoionization of $\mathrm{He}$ indicate the importance of this difference. The purely molecular model with uncoupled channels, which identifies the $2 s p+{ }^{1} P$ channel with a $2 p \pi_{\mathrm{u}}{ }^{1} P$ channel, gives an infinite $2 p / 2 s$ branching ratio while the hyperspherical model predicts a $2 p / 2 s$ ratio of 1.5 . Both results assume that only the "+" channel is populated, and with only a single channel the predicted ratios are energy independent. Calculations ${ }^{8}$ show that the " + " channel takes $\approx 98 \%$ of the oscillator strength of Rydberg series converging to the $n=2$ threshold of $\mathrm{He}^{+}$, confirming the well-established ${ }^{5}$ dominance of the "+" channel at threshold. Measurements ${ }^{7}$ show that the $2 p / 2 s$ ratio for the process

$$
\gamma+\mathrm{He} \rightarrow \mathrm{He}^{+}(n=2)+e^{-}
$$

lies between 2.5 and 0.6 for photon energies from threshold to $65 \mathrm{eV}$ above. Energy-dependent model predictions are obtained by inclusion of additional channels. Calculations indicate the weakness of additional channels: Near threshold the oscillator strength of the "-" channel is $\approx 1.7 \%$ of that of the "+" channel and that of the " $d$ " channel is negligible. ${ }^{8}$ Using the hyperspherical transition amplitudes of Ref. 2 and assuming a $1.7 \%$ uncoupled admixture of the "-" channel, we estimate the $2 p / 2 s$ ratio to lie in the range between 2.6 and 1.0, which nicely encompasses most data. ${ }^{7}$ In contrast, dynamical channel coupling must be included in the molecular model to obtain the measured ratios.
The molecular-model ratios without dynamical coupling are independent of the charges of the particles, whereas the hyperspherical ratios are not. For example, the hyperspherical $2 p / 2 s$ ratio for $\mathrm{H}^{-}$predicted for the $2 s p+{ }^{1} P$ shape resonance channel is 4.5 . A measurement of this ratio at the peak of the $\mathrm{H}^{-}$shape resonance would provide another test of the two descriptions. ${ }^{9}$

Hyperspherical estimates are also consistent with data on the average photoelectron angular distribution asymmetry parameter, ${ }^{10} \beta_{\mathrm{av}}$, for process (1). Assuming again a $1.7 \%$ admixture of the "-" channel, we estimate $\beta_{\mathrm{av}}$ to lie between 0.0 and 0.5 at threshold. Experimentally, $\beta_{\mathrm{av}} \approx 0.0$ at threshold. ${ }^{7}$

We conclude that the consistency of the molecular and diabatic hyperspherical models at small distances, which should prove useful for studies of three-particle bound and well-localized resonant states, breaks down at large distances. The experimental data discussed here favor the asymptotic representation of the hyperspherical channels.

This work was supported in part by the Department of Energy, Division of Chemical Sciences, under Grant No. DE-FG02-85ER 13440 .

Anthony F. Starace and Joseph H. Macek

Department of Physics and Astronomy

The University of Nebraska

Lincoln, Nebraska 68588

Received 29 December 1986

PACS numbers: $32.80 . \mathrm{Fb}, 31.20 . \mathrm{Tz}$

1J. M. Feagin and J. S. Briggs, Phys. Rev. Lett. 97, 984 (1986), and references therein.

2J. H. Macek, J. Phys. B 1, 831 (1968). The second and third column headings for the Table 3 amplitudes, $V_{a}$, should be switched.

${ }^{3}$ C. D. Lin, Phys. Rev. A 14, 30 (1976); C. H. Greene, J. Phys. B 13, L39 (1980).

${ }^{4}$ J. Botero and C. H. Greene, Phys. Rev. Lett. 56, 1366 (1986).

5 J. W. Cooper, U. Fano, and F. Prats, Phys. Rev. Lett. 10, 518 (1963); U. Fano, Rep. Prog. Phys. 46, 97 (1983).

${ }^{6}$ J. H. Macek, Proc. Phys. Soc. 92, 365 (1967).

${ }^{7}$ V. Schmidt, H. Derenbach, and R. Malutzki, J. Phys. B 15, L523 (1982); P. R. Woodruff and J. A. R. Samson, Phys. Rev. A 25, 848 (1982); J. M. Bizau et al., Phys. Rev. Lett. 48, 588 (1982); D. W. Lindle et al., Phys. Rev. A 31, 714 (1985).

${ }^{8}$ P. G. Burke and D. D. McVicar, Proc. Phys. Soc. 86, 989 (1965). The reduced oscillator strength ratio is calculated from Tables 2 and 3 and Eqs. (11) and (24).

${ }^{9}$ This aspect was pointed out to one of us (J.H.M.) by Dr. J. M. Feagin.

${ }^{10}$ S. T. Manson and A. F. Starace, Rev. Mod. Phys. 54, 389 (1982). 